\title{
Designing a Business Model for Environmental Monitoring Services Using Fast MCDS Innovation Support Tools
}

\author{
Tuomo Eskelinen, Teemu Räsänen, Ulla Santti, \\ Ari Happonen, and Miika Kajanus
}

\author{
"Small-scale community sustainability transitions") \\ are recognized as an important strategy toward a \\ sustainable society in general. It is now suggested, \\ that with environment monitoring and open data \\ plus information as a service, sustainable transitions \\ can be achieved with more actual details and the \\ effects of change process would be then evident.
}

Nigel Forrest and Arnim Wiek (2014)

\begin{abstract}
The free availability of open data provides opportunities to start new businesses and gain business intelligence. However, although data is often used to support decisions and actions, the possibilities offered by modern sensor technologies with connections to cloud-based data collection services are not being effectively capitalized. Data collection systems are also not generally open source solutions, even though open and flexibly adjustable systems would broaden the opportunities for solutions and larger revenue streams. In this article, we used action research methods to discover new business opportunities in a semi-open information system that utilizes environmental monitoring data. We applied a four-stage innovation process for industry, which included context definition, idea generation, and selection, and produced multi-criteria decision support (MCDS) data to help the design of business model. This was done to reveal business opportunities for an environmental monitoring service. Among these opportunities, one service-style business model canvas was identified as feasible and selected for further development. We identified items that are needed in the commercialization process of environmental monitoring services. Our process combines open environmental monitoring data, participative innovation process, and MCDS support, and it supports and accelerates a co-creative business model creation process that is cost-beneficial in terms of saving time. The results are applicable to the creation of an open data information system that supports data-driven innovation.
\end{abstract}

\section{Introduction}

Open data is a major driver for innovation. It can be used by anyone as a free public resource to start new businesses, improving existing ones, or gain business intelligence. Although the potential for innovation is large, we do not know exactly which kinds of applications will turn out to be the most promising, the most robust, and the most replicable. Therefore, we need to learn about the mechanisms of value creation and the ways in which open data fits into different companies' strategic and operating models (Gurin, 2014). The business of open data is a young field, but it holds promise for service innovation in a variety of domains (Lindman \& Nyman, 2014).

Consider the domain of environmental monitoring. Understanding the quality of available water is critical because, for example, climate change projections indicate that cities all around the world will face threats to water supply security, heightened flood risks, and severe heatwaves (Bates, 2008). Some of these impacts are already 


\section{Designing a Business Model for Environmental Monitoring Services Using Fast MCDS Tuomo Eskelinen, Teemu Räsänen, Ulla Santti, Ari Happonen, and Miika Kajanus}

being felt, and as such are no longer just a collection of projections (de Haan, 2015). To start to tackle to these challenges and to answer the questions arising with them, environmental data produced by environmental monitoring should form a basis for added knowledge, and it should give a starting point to address actual problems, not just causes (Niemi, 2009). Thus, the domain of environmental monitoring represents a rich domain for the study of open data and for the development of novel business models.

From 2016 through to 2020, the cumulative market size for open data is estimated at $€ 325$ billion (Wüstenhagen, 2006), and the availability of publicly available open environmental data is increasing rapidly. In Finland, the market for businesses related to environmental monitoring data is estimated to reach $€ 6$ billion by 2020 (Hietaniemi, 2009). Already now, legal documents, statistics, geographical data, traffic data, and environmental data are freely available for public use in Finland (Kinnari, 2013). In this context and in this study, we describe a participative business model creation process that is built on an actual Finnish case of available open data from environmental monitoring.

Environmental monitoring means measuring physical, chemical, and biological variables over time (usually over long time periods) to provide data about any possible changes and the speed of such changes on the monitored environment and its ecosystem with an aim to understand the present state of the environment and any subtle changes (Artiola, 2004). With historical data, even small indications of possible future environmental dangers can be identified with event monitoring of any current abnormal situations. Good open data about the environment also enhances decision making and supports open politics models.

From a business perspective, the demands for more green solutions and more nature-friendly ways of working have been increasing in many different industries, for example, in the area of basic infrastructures such as power generation (Niemi, 2009). Environmentally friendly companies can differentiate themselves from their competition and enhance their market share. However, companies need to understand what aspects of eco-friendliness will appear to their customers: earlier studies have shown that, for example, eco-friendly products that save energy are of interest and concern to many groups (de Haan, 2015) but products that reduce carbon dioxide emissions are less so. For example, Hornibrooks and colleagues (2015) found that putting “...carbon labels on supermarket own brand products has had no discernible impact on shifting demand to lower carbon products".

In this study, our goal was to find connections between the environmental monitoring open data and business models. Open data was seen as business value accelerator that creates new business innovation possibilities. Unlike private big data, open data is for everyone as a free public resource and can be seen as a resource to start new businesses, gain business intelligence, and improve business processes (USCCF, 2014). To enhance the usability of open data, the solutions considered in this study were limited to the application of open software solutions. Morgan and Finnegan (2014) studied the benefits of open source software, stating that the most important benefits are: high reliability and stability, lower costs, user support from the experts in the online community, flexibility in terms of customization, and avoidance of vendor lock-in.

Through customization, the use of open source software facilitates value creation and accelerates innovation and exchange of ideas, gives access to superior knowledge outside the firm, and adds flexibility of use. Innovation and idea exchange happen by opening the source code to everyone, which in turn opens the door for follow-up innovations and improvements. Superior knowledge can be obtained when the engineers of a firm work as part of a development team of a community that gives the firm access to knowledge outside their own areas of expertise. This access also provides the flexibility of using new technologies and selecting the most suitable open software components to fulfill any development needs (Morgan \& Finnegan, 2014).

Without measurements and data, it would be impossible to identify the gains of any change process. For example, in the mining sector, measurements are needed to identify environmental impacts. Also, municipal water distribution systems needs hydrological measurements to improve water safety. More data also typically generates new findings and inspires innovation, which builds possibilities for new business opportunities. New business opportunities will emerge and some old models will be revised; as van den Bergh, Truffer, and Kallis (2011) argue, "transitions research assumes that transitions are rather smooth, well-governed processes. But like all social and technological changes, transitions involve creative destruction with winners and losers."

Environmental monitoring typically combines many data sampling sources (e.g., from water, air, or soil) 


\section{Designing a Business Model for Environmental Monitoring Services Using Fast MCDS Tuomo Eskelinen, Teemu Räsänen, Ulla Santti, Ari Happonen, and Miika Kajanus}

with multiple methods of measurement and analysis, including traditional laboratory analyses, to understand the extent of chemical contamination in a certain area. Unfortunately, traditional field measurements and sampling only provide information about one given area, space, and time, and do not provide any information between samples. Furthermore, time delays with manual sampling can be days, weeks, months, or even years. The development of continuous monitoring technology has made it possible to collect data almost constantly in real time, with multiple variables being measured simultaneously. Together with sampling, laboratory analyses, and continuous field measurements, it now is possible to generate more comprehensive ways to better understand the state of environment, thereby improving overall situational awareness (Laniak et al., 2013). With publicly available data, people can understand better the state of local environment and contribute to political efforts or environmental and infrastructure construction projects. The core of the information services based on open data are data availability and usability.

By creating a new business model, a business can create new markets (Nenonen \& Storbacka, 2010). But a business model is also integral to the functioning of the business. Indeed, Magretta (2012) describes a business model as, "the story that explains how an enterprise works". It is important to ask how a business model creates value for customers through its "architecture of value creation" (Teece, 2010). Many companies fail to do this because they do not focus on market re-shaping. The challenge is to produce radical new innovations to products, services, or business models and to challenge the de-facto ideas in current markets (Nenonen \& Storbacka, 2011). Without a market re-shaping focus, the business cannot achieve high-level understanding of the actual needs of the customer and efforts for customer collaborative value creation will fail (Furr \& Dyer, 2014).

A typical business model formulation process is also an iterative learning process - it proceeds by trial and error - and studies show that this process is more effective in teams (Sosna, 2010). According to Aljena (2014), business model research is far from practical usability and the actual practices of building a business model vary greatly from detailed planning to un-planning. The big challenge is balancing the needs of different stakeholders and customer demands, and deciding how to select items correctly when creating a business model to suit these various and sometimes contradictory cases. Indeed, more research is needed to simplify the business model formation process. In this context, supportive tools, such as multi-criteria decision support (MCDS) methods, provide help with the design challenges, including the prioritization of business model items. Especially in complex interconnected cases, experimental small change based on rapid development models are needed to obtain new knowledge (Parker, 2016). For example, with environmental monitoring, where private, public, and third sector entities collaborate, a shared fairness in the solution increases the likelihood of success (Hague, 2011; Parker, 2016; Tikka \& Gävert, 2014). Business model creation in the open data business context requires applied science models on how to build new business models, which also includes the prioritization, selection, and analysis of the building blocks of the business model. To address this gap, we have identified the following research questions for this study:

1. How can a participative business model technique be used in the identification and prioritizing of business model items relating to open data from environmental monitoring?

2. Can we accelerate business model creation in an open data ecosystem with a participative business model process and multi-criteria decision support?

The remainder of this article presents environmental information services and models, and a four-phase business model creation process with multi-criteria decision support, which was done in order to build a core of a business model on environmental monitoring service.

\section{Environmental Information Services and Models}

Indeed, the availability of the data itself is only part of the story. Implementation requires the information service provider to consider technical properties and functions such as measuring devices (sensors), data transfer, data collection, data processing, methods of analysis, and modelling procedures. The information service provided has to consider means to share only the information needed by the end users. One possible model for this sort of integrated environmental modelling, monitoring, and decision process was presented by Laniak and colleagues (2013). Their model not only focuses on getting the data, it also considers a wide view of the subject by beginning from the clarification of environmental issues through to the analysis and results up until to the end, where decisions are made. At the core of the model is the integrated environmental 


\section{Designing a Business Model for Environmental Monitoring Services Using Fast MCDS Tuomo Eskelinen, Teemu Räsänen, Ulla Santti, Ari Happonen, and Miika Kajanus}

modelling stage, which includes the data collection and measurement observations, which are also the core parts of this study. In Figure 1, the main components of the integrated environmental modelling and decision process (Laniak et al., 2013) are presented, including a boundary that delineates the elements included in our proposed business model development process, as will be described in this article.

In information services, the most scalable solution is to use a cloud service for data sharing. Cloud services have rapidly developed into an important ICT technology tool that responds to the fast-growing needs of data storage and other IT resource needs. For example, cloud services are well suited to a complex platform business field, where one change affects multiple players and experimental development is needed. These rapid changes build the knowledge about the usability of the solutions (Parker, 2016). As platform business models make it possible for private, public, and third sector entities to collaborate towards a shared business goal, fairness is one of the core elements supporting the possibility for great success (Hague, 2011; Parker, 2016; Tikka \& Gävert, 2014).

Cloud-based information technology has significantly lowered entry costs of IT deployment, it connects users to a shared pool of IT resources, and it allows a higher level of elasticity, which makes IT deployment more scalable. Moreover, cloud computing lowers the innovation barriers and opens up opportunities because it is easier to involve many people to use and develop ser- vices (Testa, 2015). So, services should focus on providing ease of use for information required by the end user while ensuring that other functionalities of the system and the technologies behind the delivery process of the information fade to background. An example of an environmental information service is shown in Figure 2, including its various components (Räsänen, 2011).

Furthermore, given that the data is the base ingredient of the information services, a large effort should be directed towards availability and overall accessibility of observation data and the information that is constructed from this data. Also, different data (and information) providers should enter into deep cooperation and collaboration in order to reveal new (business) possibilities lurking inside in their costly collected data. Finally, to be truly able to provide the information as a service, open and standardized software approaches are needed for the technological solutions used as service platforms. For example, open application programming interfaces (APIs) and wide-timeframe data access are needed. These steps can improve the transparency of computational and data-processing methods (Räsänen, 2011).

In Finland, the Centre for Economic Development, Transport and the Environment (ELY Centre; ely-keskus.fi/web/ely-en) monitors environmental conditions and changes together with Finnish Environment Institute (SYKE; syke.fi). Priority is given to water systems monitoring, to the regular controlling of climate (in most areas), and to the observation of endangered

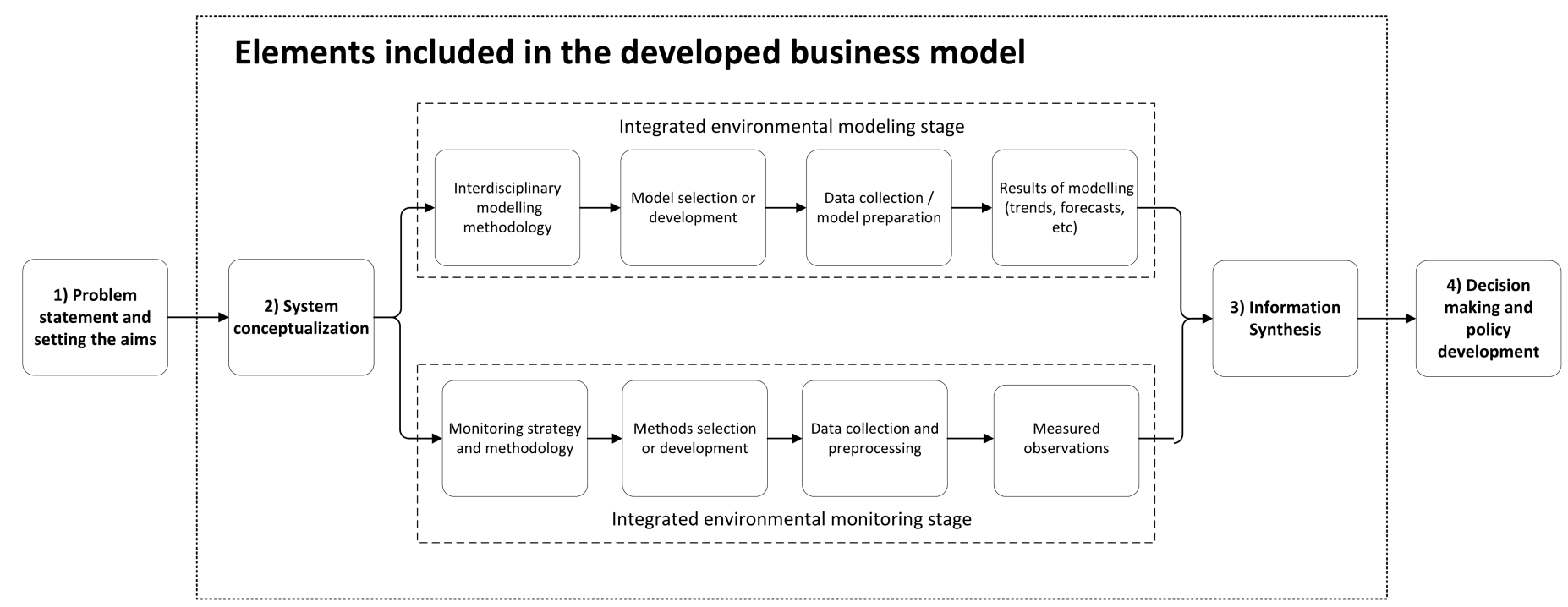

Figure 1. The main components of the integrated environment modelling and decision process (adapted from Laniak, 2013), including the proposed business model development process 


\section{Designing a Business Model for Environmental Monitoring Services Using Fast MCDS Tuomo Eskelinen, Teemu Räsänen, Ulla Santti, Ari Happonen, and Miika Kajanus}

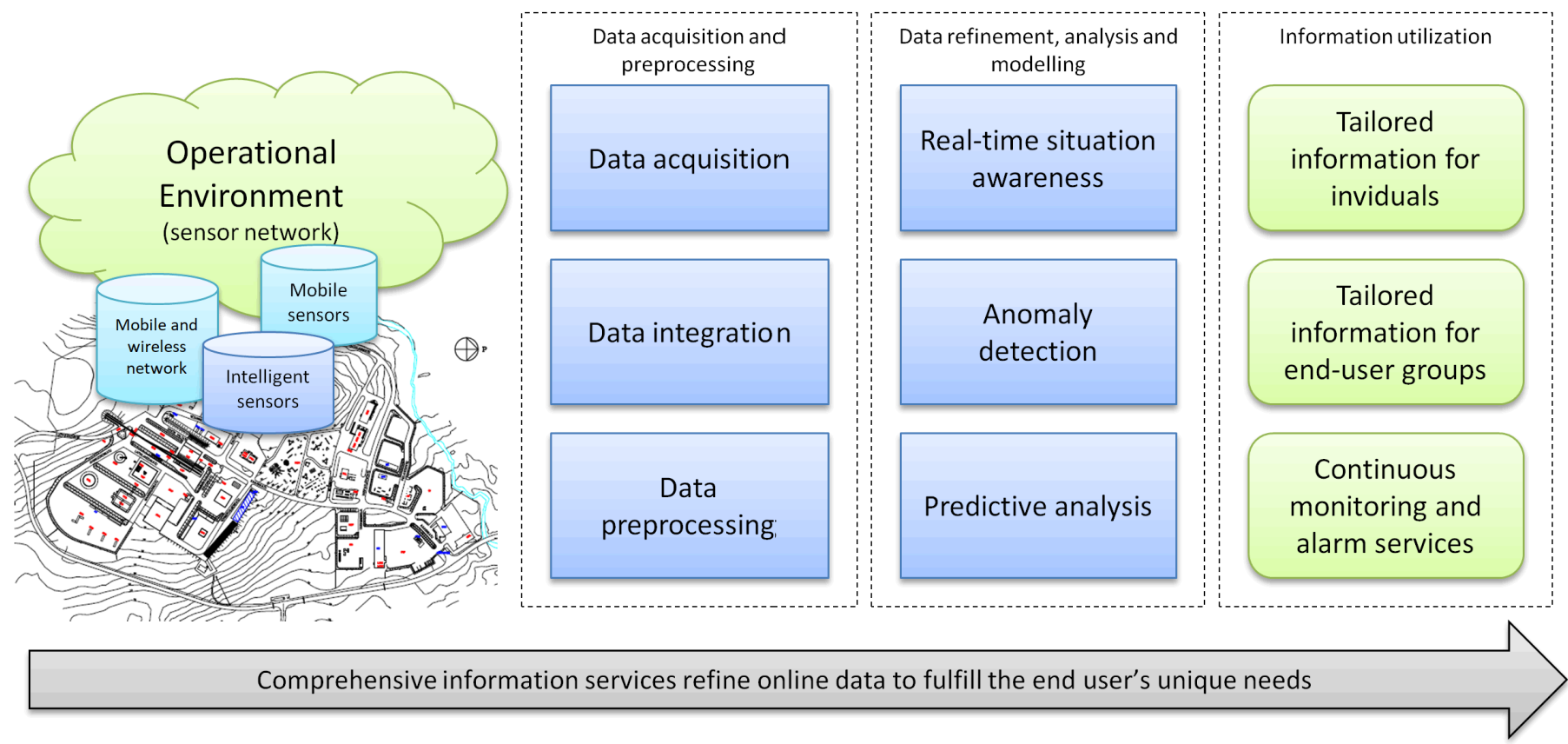

Figure 2. An example of an environmental information service and its components (Räsänen, 2011)

animals. Companies and institutions follow and report pollutants and effects caused by their actions. The data is saved in national databases, which are open for all users, but for some of them user identification is needed. The ELY Centre uses this data for decision making, forming statements, and as a basis for planning. It also analyzes and publishes information about environmental conditions in different areas of Finland.

\section{Business Model Creation and Multi-Criteria Decision Support}

Considering the possible challenges of developing new business models, practitioners would welcome a set of tools to help make the process easier. For this need, multi-criteria decision support (MCDS) methods provide transparent and coherent decision support and facilitate communication in complex situations. These methods are especially well suited to cases with conflicting objectives, multiple alternatives, and actors with uncertain or incomplete information. As they are used in the current study, MCDS methods are sometimes used with other planning tools. As an example, connecting MCDS methods with SWOT (Strengths, Weaknesses, Opportunities, and Threats) analysis can yield analytical priorities for the SWOT factors and makes them commensurable (Kajanus, 2012).
The idea of using MCDS methods within a business model canvas (Osterwalder, 2004) as a design framework is to systematically evaluate the components of a business model. This is done to identify the components with the greatest potential or importance. First, through a creative process, a set of potential items for a business model is identified and documented. After this, identified components are analyzed and prioritized. The business model canvas provides the basic framework within which an analysis of the decision situation can be performed. The MCDS method enables the creation of business models that are based on an analytical selection process. Any MCDS method, and its prioritization principles, can be applied; the existence of different techniques allows the adaptation of use of the MCDS method according to the needs of the decision maker and the specific planning situation.

The business model design process, with prioritization, starts with the identification of needs. From there, a starting point for a new business model is a description based on the business model canvas. First, the process starts with a few items and then more are added to cover all canvas blocks needed in a given context. The connections and interrelations among the items are important in this part because they help to compose a well-balanced business model. Good connections gen- 


\section{Designing a Business Model for Environmental Monitoring Services Using Fast MCDS Tuomo Eskelinen, Teemu Räsänen, Ulla Santti, Ari Happonen, and Miika Kajanus}

erate a believable business structure with an appealing value proposition. The business model itself is built upon a collection of ideas; it can be said that a business model, as expressed in a business model canvas, is a portfolio of relevant items belonging to their relevant building blocks. So, the business model design closely parallels project portfolio selection (Archer \& Ghasemzadeh, 1999; Stummer \& Heidenberger, 2003; Thore, 2002), where the organization seeks to choose projects to meet the given goals and constraints. Thanks to extensive methodological research, a broad variety of approaches exists for project portfolio selection. For more information about project portfolio selection methods, see Gustafsson and Salo (2015) and Martino (1995).

To create a core business model, robust portfolio modelling can be used to find "the best" from all the rest. Robust portfolio modelling (Liesiö, 2007; Salo, 2006) is an MCDS method designed to select ideal sets of projects (or items) to constitute a portfolio, which is a collection of items (or projects) selected from a large group of different possibilities. In its basic variant, robust portfolio modelling is a scoring model (CasadesusMasanell, 2007), which is widely employed in the evaluation and generation of a portfolio of projects, in settings where multiple objectives are required to be considered (Sosna et al., 2010). A central concept and key outcome of robust portfolio modelling is the socalled "core index", which is used to map and build an ideal portfolio from the evaluated items. The core index values indicate the most important and best-fitting items for a possibly successful business model, and is especially important when the evaluation has contrasting needs. With the help of robust portfolio modelling and core index calculations, key ideas for the different canvas blocks will be defined.

As a pragmatic solution, a four-phase approach is presented by Kajanus and co-authors (2014). In Phase 1 , the context for the business model is described and an effective process is designed. It includes decisions on the objectives, selection of participants (e.g., customers and experts), the evaluation criteria, and needs for innovation workshops or information collection (e.g., interviews). In Phase 2, a number of business model ideas are collected with multiple methods (e.g., interviews, workshops, questionnaires). In this phase, the quantity is of ideas is important. With a larger idea base, there are more seeds to help others to generate more (and better) ideas. Typical ideation is implemented as group work session with relevant stakeholders (e.g., firm CEO, decision makers, key customers, service providers). Then follows Phase 4, the analysis phase, during which a final list of the most promising items for the business model will be defined.

\section{Methods for Business Model Development}

\section{Business model development process of environmental monitoring systems}

In this section, we describe the business model generation process in the context of an environmental monitoring system, which consisted of four primary phases:

1. Defining the decision context (environmental monitoring) and preparing for a planning process involving selecting and briefing the participants and defining evaluation criteria.

2. Identifying and innovating the relevant items and new ideas for the business model to be generated, and including them in the business model analysis.

3. Determining the relative importance of the business model items (core indexing).

4. Defining the business model and then re-designing it (new items were added in four steps) with the aid of the evaluation information.

In Phase 1, the context of a business model for industrial environmental monitoring services was decided. Evaluation criteria were discussed and determined. Also, it was decided to hold a workshop for idea generation and evaluation. Because this research was done by applying action research methods, with real specialists, a workshop was organized for the experts with the researchers also participating in the event. Action research was used because the method is well suited to finding solutions to practical problems where researchers are active participants (Eriksson \& Kovalainen, 2008).

The workshop covered phase 2 and 3 of the innovation process. The purpose of the workshop was to clarify the most important business factors in (industrial) environmental monitoring services. The business model generation process in a workshop was started with an idea of open environmental monitoring platform with possible use cases. Attendees of the workshop primarily came from the mining industry and the water management sector; environmental authorities were also represented. As a starting point, it was proposed that a continuous environmental monitoring system would gather 


\section{Designing a Business Model for Environmental Monitoring Services Using Fast MCDS Tuomo Eskelinen, Teemu Räsänen, Ulla Santti, Ari Happonen, and Miika Kajanus}

the sensory data, that it would also process the data and share refined information with end users. Some of the discussed examples of possible use cases for such system were:

- observation of the infrastructure of the water distribution network and any potential leaks

- detection of changes in quality of the water in the distribution supply network

- instant messaging services to customers and citizens when problems arise

- monitoring the functioning of the water storage structures

- management of water balance in a mine production area

- detection of contamination in the water

- automated collection of information to be reported to the environmental authorities

The goal of the workshop was to develop business models for an environmental monitoring service that is based on an open information system. Ideas for the model were collected by using an extended business model canvas (described above). The ideas were fed to an online evaluation environment, and the results were analyzed with a portfolio analysis tool. The portfolio analysis gave the core indices for inputs, which were used to select the best input ideas for the business model. For this business model generation process, the Phase 1 activities and the preparation of the workshop were started about six months before in a preparation group managed by the project leader. The 19 workshop participants were from private companies and associations (4), public environmental administration organizations (3), universities (11), and regional development companies (1).

In Phase 2, as a kick-start for idea generation, a possible scenario of a monitoring service based on open data sources was presented to the participants. This was followed by an idea generation session. To support the idea generation and to give a clear framework for where to position new ideas, items for the business model were allocated into an expanded business model canvas (Kajanus et al., 2014), where the structure of the business model is divided into 12 business model blocks. To support Phase 3, the ideas were imported into an online evaluation environment: the InTo tool (Kajanus et al., 2014) where the participants evaluated the ideas with a visual evaluation tool. In this particular evaluation, two evaluation criteria were used, which were earlier agreed in Phase 1: i) business potential and ii) customer need/benefit. The evaluator gave each idea values from 1 (low perceived value) to 7 (high perceived value) against the evaluation criteria using the online evaluation tool. After Phase 3 was completed, calculated results values from the evaluation were used in the decision-making analysis. Finally, in Phase 4, the best ideas were chosen to form the core business model.

\section{Results}

The workshop participants generated new ideas and subsequent idea evaluation by the participants resulted in 11 to 15 evaluations of each idea. The best ideas were selected to be applied to the canvas in four steps according to core index, which resulted in a prioritized list of ideas starting from best core index. First, the best 4 ideas were applied to the canvas, which were: a full solution for industrial use (company solution), a startto-end full monitoring chain solution with sensor (key function), an information-based data and end-user service (customer relations item), and process industry companies (customer segment).

Second, the following items were added to the canvas: ease of use and time saving (value proposition), collaboration model (customer relationships), and service providers, for example, in areas of ICT and data analysis (key resources).

Third, the following items/ideas were added to the model: easily modified turnkey solution (customer need), experts (resources), continuity and support (key activity), and Internet and direct contacts (channels). Adding these items resulted in the core business model canvas, which is presented in Figure 3.

\section{Discussion}

In this business model, the customer segment should be in an industrial context (e.g., water production facilities or industrial operators). In evaluator comments, it was suggested that industry would want to buy comprehensive services, not just measurement devices. Even when the companies would have different needs, from a system and service point of view, many base components of the service could be the same for all. In this context, only the outcome of the service should be tailored 


\section{Designing a Business Model for Environmental Monitoring Services Using Fast MCDS Tuomo Eskelinen, Teemu Räsänen, Ulla Santti, Ari Happonen, and Miika Kajanus}

\author{
Customer Need \\ Ready and easy to use, customized product \\ Automatization of data analysis, predictive information
}

\section{Company Solutions}

Full-service package for company needs

Reporting services

\begin{tabular}{|c|c|c|}
\hline Key Partners & Offering & Key Tasks \\
\hline $\begin{array}{l}\text { Meter and sensor } \\
\text { manufacturers, } \\
\text { authorities, ITC and } \\
\text { automation systems }\end{array}$ & $\begin{array}{l}\text { Easy to use, saving } \\
\text { time, useful } \\
\text { information available }\end{array}$ & $\begin{array}{l}\text { Ensure the } \\
\text { monitoring } \\
\text { chain and o } \\
\text { stability, gu } \\
\text { continuity }\end{array}$ \\
\hline \multicolumn{2}{|l|}{ Key Resources } & \\
\hline \multicolumn{2}{|c|}{$\begin{array}{l}\text { Service providers e.g., software, knowledge } \\
\text { transfer and accounting, experts in the field, } \\
\text { environmental measurements and data, } \\
\text { production }\end{array}$} & \\
\hline \multicolumn{3}{|l|}{ Cost Structure } \\
\hline \multicolumn{3}{|c|}{ System development and maintenance } \\
\hline
\end{tabular}

\section{Competing Solutions}

Commercial information systems

Figure 3. Extended business model canvas (adapted from Kajanus et al., 2014) for the core environmental monitoring solution

to fulfill customer needs, meaning the ways the data is analyzed and presented. Moreover, related to service usability, the information service offered has to be able to guarantee continuity. It might possibly be an open architecture system, which can be maintained and developed by several actors without sharing data, and that approach would also make the system itself more adjustable and continuous. Monitoring on its own is not that interesting to customers; they are interested in easy ways of reading and interpreting the results. Big actors, such as those from the mining industry, seek reporting that would be directly available for the authorities: a system generating environmental reports would support faster and easier operations. One identified problem in the Finnish system was that both the private and public organizations and environmental authorities have several information systems, which together generate huge amounts of data and measurement services. To increase cost-efficiency, human labour should be focused in the last steps of the monitoring chain (e.g., conclusions based on data analysis and automated reports).
Cash Flow

Improved risk management, preventing and minimizing (environmental) damages

\section{Customer}

Relationships

Refined measuring

data, long-term

customer relationships

\section{Channels}

Internet, direct

contacts, sensor

supplier
Customer Segments

Companies and industrial sector
The workshop created wide discussion and resulted in insights on essential business items. The feedback was that the working method is efficient and that the InTo tool accelerated idea evaluation and prioritization in a systematic way. The presentation of business model in a canvas made the model visible in a compact and easily understandable way.

After the workshop, the Savonia University of Applied Sciences (portal.savonia.fi/amk/en) launched a European Union funded project (Water-M project in ITEA-3 program; itea3.org/project/water-m.html), which has built an information service in accordance with the proposed business model. In this project, a demonstration of an online water distribution network monitoring service was built in close co-operation with Kuopio Vesi water works (kuopionvesi.fi). The monitoring service was created using an open source software platform which has been published already in the GitHub software development platform. This information service is now under the evaluation of end-users and business actions are currently in progress. 


\section{Designing a Business Model for Environmental Monitoring Services Using Fast MCDS Tuomo Eskelinen, Teemu Räsänen, Ulla Santti, Ari Happonen, and Miika Kajanus}

\section{Conclusions}

We were able to integrate open data from environmental monitoring and a participative business model creation process. This is an empirical approach to help find new ideas and produce business models in an open data context by relying on open source application ideologies. The novel contribution is the process and how it starts from typical idea generation, but then enhances the business model quality by workshopping with area experts that both evaluate and prioritize the ideas. The MCDS decision support tools are then applied to the evaluations for sensitivity analysis, which results in a core indexed business model framework including only the most promising idea seeds.

The innovation process proved to be a useful method and tool that supports open innovation in idea generation, fast evaluation and development of ideas, and finally, identification of the core business model. Core items of a business model were identified and prioritized in one-day in a workshop, which is a relatively short time, and added value. Decision supportive data was available at the end of the workshop day, which helped to prioritize business model items, and also facilitated discussion on the core business model. Core items of a service-for-industry business model on environmental monitoring were identified, and this structure will be used when further developing the business model.

\section{Acknowledgements}

The project was partly funded by the European Social Fund.

\section{About the Authors}

Tuomo Eskelinen, $\mathrm{PhD}$, works as an RDI Advisor at the Savonia University of Applied Sciences in Finland. His background is in Environmental Sciences, and his expertise and research interests include sustainable value networks, development of business partnerships, and sustainable business models. He organizes research, development, and innovation processes with enterprises and other organizations, with scientists, end users, and customers, from idea generation to business models development and commercialization. He has participated in more than $20 \mathrm{EU}$-funded projects in the fields of forestry, energy, food, water safety, and processing. He is experienced in performing and coordinating interdisciplinary, international, large-scale research projects, workshops and training.

Teemu Räsänen, D.Sc. (Tech), works as a Senior Lecturer at the Savonia University of Applied Sciences (UAS) in Finland. His background is in Environmental Technology, and his expertise and research interests include environmental informatics, environmental monitoring, data analysis, data mining and developing online monitoring systems. Within this context, his main focus is in the fields of water management, monitoring the impacts of industrial emissions, and waste management. He is also the head of Savonia UAS environmental technology degree program, which includes about 170 students annually.

Ulla Santti, MSc (Econ), has experience as a teacher of Business Administration and Marketing, and she is an expert on research, development, and innovation projects at the Savonia University of Applied Sciences in Finland. She has also undertaken SME business development through practical fieldwork in healthcare, industrial factories, advertising, and the tourism industries. Currently, she is preparing her doctoral thesis at the Lappeenranta University of Technology, Finland. Her research interest includes business models and organizational culture development of SMEs with an interest in what kind of common ground, effects, and connections these concepts have on each other.

\section{Continued on next page...}




\section{Designing a Business Model for Environmental Monitoring Services Using Fast MCDS} Tuomo Eskelinen, Teemu Räsänen, Ulla Santti, Ari Happonen, and Miika Kajanus

\section{About the Authors (continued)}

Ari Happonen, DSc (Tech), is the Head of Computer Science Bachelor programme in the Lappeenranta University of Technology's (LUT) School of Business and Management, Finland. Ari has been working at LUT for more than 15 years, participating in numerous RDI projects with Finnish and international companies in the contexts of international logistics services, consumer products industries, service development, innovation facilitations and mentoring, consultation, business development, mobile service development, construction industries, digitalization, public-private collaboration R\&D efforts, and so on. Ari has a long history working as an intermediate and collaboration facilitator in interdisciplinary projects, workshops, innovation facilitation, development mentoring, teaching, and training and has also acted as the LUT Project Manager for the Akseli project, providing the base knowledge for this publication.

Miika Kajanus works as an RDI-liaison in Savonia University of Applied Sciences in Finland. The role is in international RDI funding in Savonia's focus areas related to food, water, health, industry, and bio products. The main tasks are to organize research, development, and innovation processes with enterprises and other organizations. The work involves collaboration with scientists, SMEs, inventors, end users, and experts aiming in a straightforward way to implement innovations including all the phases starting from idea generation, conceptualization, business models development, and commercialization. Since 2004, he has been involved in more than 100 innovation commercialization projects, and he has more than twenty international research publications. He is one of the creators of the InTo innovation tool.

\section{References}

Aljena, A. 2014. Business Model Designing Tool - Filling the Gap between Philosophy and Reality. Paper presented at the Innovate Teaching in Business \& Management Conference, April 2014, Gdansk, Poland.

Archer, N., \& Ghasemzadeh, F. 1999. An Integrated Framework for Project Portfolio Selection. International Journal of Project Management, 17(4): 207-216. http://10.1016/S0263-7863(98)00032-5

Artiola, J., Pepper, I. L., \& Brusseau, M. L. 2004. Environmental Monitoring and Characterization. San Diego, CA: Elsevier Academic Press.

Bates, B., Kundzewicz, Z., Wu, S., \& Palutikof, J. (Eds.). 2008. Climate Change and Water. Geneva: Intergovernmental Panel on Climate Change (IPCC) Secretariat.

Biber, E. 2011. The Problem of Environmental Monitoring. University of Colorado Law Review, 83(1): 1-82.

Casadesus-Masanell, R., \& Ricart, J. E. 2007. Competing through Business Models. IESE Business School Working Paper No. 713. Pamplona, Spain: University of Navarra.

de Haan, F. J., Rogers, B. C., Frantzeskaki, N., \& Brown, R. R. 2015. Transitions through a Lens of Urban Water. Environmental Innovation and Societal Transitions, 15: 1-10. https://doi.org/10.1016/j.eist.2014.11.005

Eriksson, P., \& Kovalainen, A. 2008. Qualitative Methods in Business Research. London: SAGE Publications.

Forrest, N., \& Wiek, A. 2014. Learning from Success-Toward Evidence-Informed Sustainability Transitions in Communities. Environmental Innovation and Societal Transitions, 12: 66-88. http://doi.org/10.1016/j.eist.2014.01.003

Furr, N., \& Dyer, J. 2014. The Innovator's Method: Bringing the Lean Startup into Your Organization. Boston, MA: Harvard Business Review Press.

Gurin, J. 2014. Driving Innovation with Open Data. Washington, DC: U.S. Chamber of Commerce Foundation.

Gustafsson, J., \& Salo, A. 2005. Contingent Portfolio Programming for the Management of Risky Projects. Operations Research, 53(6): 946-956.

http://doi.org/10.1287/opre.1050.0225

Haque, U. 2011. The New Capitalist Manifesto: Building a Disruptively Better Business. Boston, MA: Harvard Business Press.

Hietaniemi, L. 2009. Visio suomalaisen laboratoriotoiminnan mahdollisuuksista. Kemian päivät. Vantaa, Finland: Green Net Finland.

Hornibrook, S., May, C., \& Fearne, A. 2015. Sustainable Development and the Consumer: Exploring the Role of Carbon Labelling in Retail Supply Chains. Business Strategy and the Environment, 24(4): 266-276.

http://doi.org/10.1002/bse.1823

Kajanus, M., Iire, A., Eskelinen, T., Heinonen, M., \& Hansen, E. 2014. Business Model Design: New Tools for Business Systems Innovation. Scandinavian Journal of Forest Research, 29(6): 603-614.

http://dx.doi.org/10.1080/02827581.2014.949301 


\section{Designing a Business Model for Environmental Monitoring Services Using Fast MCDS Tuomo Eskelinen, Teemu Räsänen, Ulla Santti, Ari Happonen, and Miika Kajanus}

Kajanus, M., Leskinen, P., Kurttila, M., \& Kangas, J. 2012. Making Use of MCDA Methods in SWOT Analysis - Lessons Learnt in Strategic Natural Resources Management. Forest Policy and Economics, 20: $1-9$.

Kinnari. T. 2013. Open Data Business Models for Media Industry Finnish Case Study. Master's Thesis. Helsinki: Aalto University School of Business.

Laniak, G. F, Olchin, G., Goodall, J., Voinov, A., Hill, M., Glynn, P., Whelan, G., Geller, G., Quinn, N., Blind, M., Peckham, S., Reaney, S., Gaber, N., Kennedy, R., \& Hughes, A. 2013. Integrated Environmental Modeling: A Vision and Roadmap for Future Environmental Modelling \& Software, 39: 3-23. http://dx.doi.org/10.1016/j.envsoft.2012.09.006

Liesiö, J., Mild, P., \& Salo, A. 2007. Preference programming for robust portfolio modeling and project selection. European Journal of Operational Research, 181(3): 1488-1505. http://dx.doi.org/10.1016/j.ejor.2005.12.041

Lindman, J., \& Nyman, L. 2014. The Businesses of Open Data and Open Source: Some Key Similarities and Differences. Technology Innovation Management Review, 4(1): 12-17. http://timreview.ca/article/757

Lintukangas, K., Kähkönen, A.-K., \& Ritala P. 2014. Supply Risks as Drivers of Green Supply Management Adoption. Journal of Cleaner Production, 112(30): 1901-1909. http://dx.doi.org/10.1016/j.jclepro.2014.10.089.

Magretta. J. 2002. Why a Business Model Matters? Harvard Business Review, 80(5): 86-92.

Martino, J. P. 1995. Research and Development Project Selection. New York: John Wiley and Sons.

Morgan, L., \& Finnegan, P. 2014. Beyond Free Software: An Exploration of the Business Value of Strategic Open Source. Journal of Strategic Information Systems, 23(3): 226-238. http://dx.doi.org/10.1016/j.sis.2014.07.001

Nenonen, S., \& Storbacka, K. 2010. Markkinamuotoilu. Johdatko markkinoita vai johtavatko markkinat sinua? Hämeenlinna, Finland: WSOYpro.

Niemi, J. (Ed). 2009. Environmental Monitoring in Finland 2009-2012. The Finnish Environment, 12. Helsinki: Finnish Environment Institute.

Osterwalder, A. 2004. The Business Model Ontology - A Proposition in a Design Science Approach. PhD Thesis. Lausanne, Switzerland: University of Lausanne.

Parker, G. G., van Alstyne, M. W., \& Choudary, S. P. 2016. Platform Revolution. New York: W.W. Norton \& Company Ltd.
Räsänen, T. 2011. Intelligent Information Services in Environmental Applications. Doctoral Thesis C 403. Oulu, Finland: University of Oulu.

Salo, A., Mild, P., \& Pentikäinen T. 2006. Exploring Causal Relationships in an Innovation Program with Robust Portfolio Modeling. Technological Forecasting \& Social Change, 73(8): 1028-1044.

https://doi.org/10.1016/j.techfore.2006.03.005

Sosna, M., Trevinyo-Rodríguez, R. N., \& Velamuri, S. R. 2010. Business Model Innovation through Trial-and-Error Learning: The Naturhouse Case. Long Range Planning, 43(2-3): 383-407. https://doi.org/10.1016/j.lrp.2010.02.003

Stummer, C., \& Heidenberger, K. 2003. Interactive R\&D Portfolio Analysis with Project Interdependencies and Time Profiles of Multiple Objectives. IEEE Transactions on Engineering Management, 50(2): 175-183. https://doi.org/10.1109/TEM.2003.810819

Teece, D. J. 2010. Business Models, Business Strategy and Innovation. Long Range Planning, 43(2-3): 172-194.

https://doi.org/10.1016/j.lrp.2009.07.003

Testa, F., Iraldo, F., Vaccari, A., \& Ferrari, E. 2015. Why Eco-labels Can Be Effective Marketing Tools: Evidence from a Study on Italian Consumers. Business Strategy and the Environment, 24(4): 252-265. https://doi.org/10.1002/bse.1821

Thore, S. A. (Ed). 2002. Technology Commercialization: DEA and Related Analytical Methods for Evaluating the Use and Implementation of Technical Innovation. Boston: Kluwer Academic Publishers.

Tikka, V., \& Gävert, N. 2014. Arvonluonnin uusi aalto. Näin rakennetaan tämän vuosisadan arvokkaimmat yritykset. Tekeskatsaus 309/2014. Helsinki: Tekes.

USCCF. 2014. The Future of Data-Driven Innovation. Washington, DC: U.S. Chamber of Commerce Foundation (USCCF). https://www.uschamberfoundation.org/sites/default/files/Data\% 20Report\%20Final\%2010.23.pdf

van den Bergh, J. C. J. M., Truffer, B., \& Kallis, G. 2011. Environmental Innovation and Societal Transitions: Introduction and Overview. Environmental Innovation and Societal Transitions, 183(3): 1488-1505.

https://doi.org/10.1016/j.eist.2011.04.010

Wüstenhagen, R., \& Bilharz, M. 2006. Green Energy Market Development in Germany: Effective Public Policy and Emerging Customer Demand. Energy Policy, 34(13): 1681-1696. https://doi.org/10.1016/j.enpol.2004.07.013 


\section{Academic Affiliations and Funding Acknowledgements}

Canadà
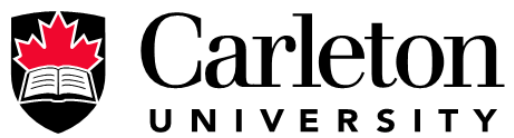

U N I V E R S I T Y

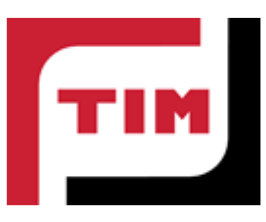

The Federal Economic Development Agency for Southern Ontario (FedDev Ontario; feddevontario.gc.ca) is part of the Innovation, Science and Economic Development portfolio and one of six regional development agencies, each of which helps to address key economic challenges by providing regionallytailored programs, services, knowledge and expertise.

- The TIM Review receives partial funding from FedDev Ontario's Investing in Regional Diversification initiative.

Technology Innovation Management (TIM; timprogram.ca) is an international master's level program at Carleton University in Ottawa, Canada. It leads to a Master of Applied Science (M.A.Sc.) degree, a Master of Engineering (M.Eng.) degree, or a Master of Entrepreneurship (M.Ent.) degree. The objective of this program is to train aspiring entrepreneurs on creating wealth at the early stages of company or opportunity lifecycles.

- The TIM Review is published in association with and receives partial funding from the TIM program. 